proportion have no pattern in time and are associated with stigmata of duct ectasia periductal mastitis. The other patterns we recognise are Tietze ${ }^{1}$ syndrome, trauma, sclerosing adenosis, and cancer (pain was the first symptom in 12 of 140 cancers, sometimes preceding other symptoms by many months). We shall shortly be reporting the diagnostic features of these various syndromes. Our clinical observations have been carried out in parallel with a questionnaire assessment of psychoneurotic traits" which shows overall that $80^{\prime \prime}$ " of these patients have no gross psychological abnormalities.

We conclude that the presenting symptom of mastalgia is not purely functional and deserves the usual investigation and attempt at diagnosis that are appropriate to other breast complaints.

P E PREeCE

R E MANSEL

L E Hughes

I H GRAvelle

Welsh National School of Medicine,

Cardiff Tietze, A, Berliner klinische Wochenschrift, 1921, 58,

Crown, S, and Crisp, A H, British fournal of Psyihiatry, 1966, 112, 917

\section{Pseudomonas aeruginosa in hospital pharmacies}

SIR,-The letter from Dr D C Shanson (17 April, p 958) reminded me of a similar incident in another London hospital that came to my notice some two years before the one which he describes.

It had been noticed over a period of some weeks that the tracheostomies of patients in the intensive care unit almost inevitably became colonised by Pseudomonas aeruginosa followed in some instances by an overt respiratory tract infection with this organism. A search of the unit resulted in the isolation of $P$ s aeruginosa from an unopened bottle of mouthwash and, following this lead, a large stock bottle of the mouthwash (closed by a bare cord) was discovered in the hospital pharmacy. Ps aeruginosa was also isolated from the contents of this stock bottle and from the cork. All of the environmental isolates and most of those from the patients were indistinguishable by phage or serological typing. The elimination of this source of infection was followed by a marked fall in the number of pseudomonas infections in the intensive care unit.

It is interesting to note that the warning given by Hughes ${ }^{1}$ against the possible use of contaminated mouthwash had already been justified by this event.

J V DADSWELL

Public Health Laboratory,

Royal Berkshire Hospital,

Reading

1 Hughes, M H, Lancet, 1972, 1, 210.

\section{Warning of severe asthma attacks}

SIR,-I should like to comment on the paper on asthma deaths in Cardiff by $\mathrm{Dr} \mathrm{J} B \mathrm{Mac}-$ Donald and others (19 June, p 1493).

I am myself an asthmatic who has had to be admitted to hospital twice this year with severe attacks. As the authors indicate, the onset of bad attacks is often rapid and it is difficult to predict when an attack will become severe on subjective symptoms alone. I have found from personal experience that the use of a peak flow meter is the best predictive instrument. A notable reduction in peak flow rate seems to occur before the symptoms become very severe and may give notice of an attack which is going to require medical help. I am now inclined to alert my doctor if my peak flow drops below $140 \mathrm{l} / \mathrm{min}$. I would suggest that severe asthmatics be issued with peak flow meters and encouraged to keep a graphic record of their peak flow morning and evening and to inform their doctors immediately this drops below whatever their accustomed level is.

The use of a peak flow meter might also obviate calling the doctor when it is unnecessary. One can have quite severe asthmatic symptoms which prove to be transient, but on subjective evidence alone it is very difficult to tell which attacks are going to pass off and which are going to require medical help. Those who are reluctant to summon medical help in time, as obviously happened in some of the Cardiff cases, would find it useful to have an objective measurement which would indicate that they were not bothering the doctor unnecessarily.

Warneford Hospital

Headington, Oxford

Pathological parasites in food handlers

SIR,-The otherwise valuable report by Dr A P Hall and others on intestinal parasites (19 June, p 1542) is marred by the incorrect conclusion that screening is desirable. The Public Health Laboratory Service, the majority of delegates to a WHO seminar on food hygiene, and most doctors working in the food industry in the UK all condemn such screening as being ineffective.

The widespread prevalence of parasites so ably demonstrated by the authors should be seen as justifying appropriate expenditure on adequate toilet facilities and confirms the importance of sound hygiene training and disciplines among food handlers. Such measures are effective and do not waste money which comes ultimately from the consumer.

JOSEPH L KEARNS

London W14 Head of Health and Safety, J Lyons Group of Companie

Unexplained hepatitis following halothane

SIR,-Dr W K Slack (19 June, p 1532) raises an interesting point in the story of unexplained hepatitis following halothane. He suggests that it might be rewarding to consider whether hypoxia may have occurred during the course of the anaesthetic. The same idea has occurred to me and no doubt to many others. Some years ago I began to wonder whether the techniques of administration were receiving a fair share of attention.

The liver may be particularly vulnerable to hypoxia because of its dual blood supply from the hepatic artery and portal vein; the mixing of these two sources results in the liver being normally exposed to a lowered oxygen environment. In certain pathological conditionsfor example, in congestive cardiac failure-an increased systemic venous pressure subjects the liver to a state of stagnant hypoxia and a centrilobular pattern of hepatic pathology is set in train. An anoxaemic anoxic state will be expected to produce a similar pattern.

Halothane is a powerful cardiorespiratory depressant. With spontaneous ventilation a patient can all too easily reach a state of hypoxia and profound hypotension which can be accentuated by positioning on the table. Is it not reasonable to suggest that the combination of a lowered alveolar oxygen tension and reduced tissue oxygen availability could provide the appropriate conditions for liver failure according to the degree and duration of exposure?

Although I am no longer directly employed in anaesthetic practice, I am interested in following the search for a solution to this mysterious ailment. Whenever I gave a halothane anaesthetic I was always impressed with its ease of administration and often I wondered whether this was its gravest danger.

\section{F C SHELley}

Bovingdon, Herts

SIR,-With reference to the article by Dr R M Galbraith and others (19 June, p 1495) it is worth placing on record that there have been three patients in Newcastle who, although negative for hepatitis-B surface antigen, have

SIR,-When someone as eminent as Professor Ian Donald draws our attention to the inadequacy of post-operative analgesia (leading article, 19 June, p 1491) then those responsible for the welfare of patients should pull their fingers out smartly, and we should be grateful to him for trying to ease us out of our habitual attitudes and take stock.

After the 1945 war there were many thousands of patients with tuberculosis, many of whom came to surgery for the then fashionable three-stage thoracoplasty, performed under analgesia, a formidable prospect for the and drugs was limit that diamorphine was the drug of choice, both before and after operation. It provided not only excellent analgesia but also that mental tranquillity which was such an essential feature for patients who knew they must endure three such episodes at short intervals. I always believed that much of their calm courage was due in no little measure to the use of this drug, and so satisfactory was it that it passed into use for all forms of thoracic surgery for the next quarter of a century, proving overall a which were neither as efficacious, nor as free of side effects.

well remember many years ago Ronald Jarman proclaiming to a meeting of anaesthetists in Dublin that diamorphine was the "only analgesic" for him after his major operation. never saw a case of addiction, as patients were end by making a plea used, and I would use be made of this excellent calming analgesic.

\section{LAURENCE O MOUNTFORD}

Emsworth, Hants

Hepatitis in patients with chronic renal failure 